\title{
FUNCTIONAL ARCHITECTURES FOR THE INTERNET OF THINGS: FUNDAMENTAL MODELS
}

\section{MAURICIO ORLANDO BERMÚDEZ, OCTAVIO JOSÉ SALCEDO PARRA \& ALBERTO ACOSTA LÓPEZ}

Faculty of Engineering, Universidad Distrital Francisco José de Caldas, Bogotá, Colombia

ABSTRACT
Being the Internet of Things an interconnection of computer equipment integrated in everyday objects, which allows them
to send and receive data through cyberspace, this article proposes an evaluation about the different fundamental
architectures that exist to model said network IoT, facilitating the connectivity of devices with Machine-to-Machine M2M
technology. The main models are analyzed and their relevant characteristics are identified in the light of the Quality of
Service metric QoS, with the purpose of recognizing which have the potential for the syntactic and semantic
interoperability of the mentioned machines, better known as "smart appliances".
KEYWORDS: Internet of Things IoT, IoT architecture, functional architecture, Quality of Service QoS \& M2M

Received: Nov 21, 2020; Accepted: Dec 11, 2020; Published: Dec 31, 2020; Paper Id.: IJMPERDDEC202071

\section{INTRODUCTION}

The Internet of Things IoT has become an opportune resource for the permanent connectivity of the generality of existing objects in nature and civilizations, specifically low-consumption electronic devices through Machine-toMachine technology M2M, facilitating its corresponding identification, monitoring and management (ETSI, 2013, 12).

This article proposes an evaluation about the different basic functional architectures of the Internet of Things IoT, which have been developed supported in the machine-to-machine M2M technology. Consequently, network models whose basic architecture considered the functional aspects of Quality of Service QoS, such as the design approach, the network hierarchy, the connectivity scheme, the interior processing, were selected. of the network, the complexity of QoS and the progress in its definition, so that QoS has been established as a metric to discuss the various architectures (Jin, et al., 2012, 3).

Expected as a result the identification of one or more functional architectures as the most appropriate to use as a framework in the development of syntactic and semantic interoperability of smart devices -also called "smart appliances"- (ETSI, 2017, 6).

\section{BACKGROUND}

The Internet of Things IoT is considered as a network of networks, since it allows the connection of individual data communication systems, with others that have security, analysis and management in various domains such as transport, energy, education, business, home, etc. (Evans, 2011, 4).

The IoT makes the Internet sensorial, by detecting and capturing signals (temperature, pressure, light, etc.) 
through electronic nano-devices called sensors. (Evans, 2011, 6), which transmits to servers through established protocols, so that these machines convert them into data, collect them, analyze them and finally, distribute them on a massive scale so that people process this information and generate knowledge (ibid, 7).

The IoT is bound to overcome various obstacles in its evolution, such as:

- Self-sufficiency in energy by the sensors.

- The implementation of IPv6 to assign unique addresses to both new and existing sensors.

- The agreement on standards especially in terms of security, privacy, architecture and communications (Evans, 2011, $10)$.

To safeguard the first impediment, the large electronics multinationals are investigating micro and nano components that optimize the energy requirements of the sensors. Regarding the second difficulty, the implementation of the new IP version is a matter of time for its expansion and consolidation, given that it is not the devices that require the only address, but the connection interfaces.

Regarding the last obstacle to the evolution of the IoT, companies, governments, standardization bodies and universities are investigating in synergy to achieve interoperability according to a common set of standards (ibidem), which at the level of fundamental functional architectures stand out in the following models:

- Objects connected by services API

- Stratification with service layer

- Networks applied to smart city

- Autonomous

- Ubiquitous

- Layer of application overlap

- Services oriented

- Advanced long-term evolution LTE-A

- Three layers oriented to services

- WSN wireless sensors

- Sensors with message queuing transport by MQTT-SN telemetry

- Fiber and wireless FiWi

- Software-defined wireless

\section{RELATED JOBS}

The research articles in Table 1 are related to this work and serve as the theoretical framework of it:

Table 1: Works related to research

\begin{tabular}{|l|l|l|l|}
\hline No. & Author & $\begin{array}{l}\text { Investigation paper } \\
\text { (title) }\end{array}$ & \multicolumn{1}{|c|}{$\begin{array}{c}\text { Network } \\
\text { architecture }\end{array}$} \\
\hline 1 & $\begin{array}{l}\text { Inge } \\
\text { Grønbæk }\end{array}$ & $\begin{array}{l}\text { Architecture for the } \\
\text { Internet of Things } \\
\text { (IoT): API and } \\
\text { interconnect }\end{array}$ & $\begin{array}{l}\text { Objects connected } \\
\text { by services API }\end{array}$ \\
\hline
\end{tabular}




\begin{tabular}{|c|c|c|c|}
\hline 2 & $\begin{array}{|ll|}\text { Duan R., } & \text { Rhen } \\
\text { X., } \\
\text { Xing T. }\end{array}$ & $\begin{array}{l}\text { QoS Architecture for } \\
\text { IOT }\end{array}$ & $\begin{array}{l}\text { Stratified with } \\
\text { service layer }\end{array}$ \\
\hline 3 & $\begin{array}{l}\text { Jin J., } \\
\text { Gubbi J., et. } \\
\text { al. }\end{array}$ & $\begin{array}{l}\text { Network } \\
\text { Architecture and } \\
\text { QoS Issues in the } \\
\text { Internet of Things for } \\
\text { a Smart City }\end{array}$ & $\begin{array}{l}\text { Applied to smart } \\
\text { city (Autonomous, } \\
\text { Ubiquitous, etc.) }\end{array}$ \\
\hline 4 & $\begin{array}{l}\text { Wali P., } \\
\text { Das D. }\end{array}$ & $\begin{array}{l}\text { A Novel Access } \\
\text { Scheme for IoT } \\
\text { Communications in } \\
\text { LTE-Advanced } \\
\text { Network }\end{array}$ & $\begin{array}{l}\text { Long } \quad \text { Term } \\
\text { Evolution } \\
\text { Advanced } \\
\text { LTE-A }\end{array}$ \\
\hline 5 & $\begin{array}{l}\text { Li L., Li S., } \\
\text { Zhao S. }\end{array}$ & $\begin{array}{l}\text { QoS-Aware } \\
\text { Scheduling of } \\
\text { Services-Oriented } \\
\text { Internet of Things }\end{array}$ & $\begin{array}{l}\text { Service-oriented } \\
\text { Three-layer }\end{array}$ \\
\hline 6 & $\begin{array}{l}\text { Ezdiani S., } \\
\text { Acharyya } \\
\text { I., et. al. }\end{array}$ & $\begin{array}{l}\text { An IoT Environment } \\
\text { for WSN Adaptive } \\
\text { QoS }\end{array}$ & $\begin{array}{l}\text { WSN } \quad \text { wireless } \\
\text { sensors }\end{array}$ \\
\hline 7 & $\begin{array}{l}\text { Govindan } \\
\text { K., Prakash } \\
\text { A. }\end{array}$ & $\begin{array}{l}\text { End-to-end Service } \\
\text { Assurance in loT } \\
\text { MQTT-SN }\end{array}$ & $\begin{array}{lr}\text { Sensors } & \text { Network } \\
\text { Message } & \text { Queue } \\
\text { Transport } & \text { by } \\
\text { Telemetry } & \text { MQTT- } \\
\text { SN } & \\
\end{array}$ \\
\hline 8 & $\begin{array}{l}\text { Liu J., Guo } \\
\text { H., et. al. }\end{array}$ & $\begin{array}{l}\text { New Perspectives on } \\
\text { Future Smart FiWi } \\
\text { Networks: } \\
\text { Scalability, } \\
\text { Reliability and } \\
\text { Energy Efficiency }\end{array}$ & $\begin{array}{l}\text { Fiber and Wireless } \\
\text { FiWi }\end{array}$ \\
\hline 9 & $\begin{array}{l}\text { El-Mougy } \\
\text { A., et. al. }\end{array}$ & \begin{tabular}{|l|} 
Software-Defined \\
Wireless Network \\
Architectures for the \\
Internet-of-Things
\end{tabular} & $\begin{array}{l}\text { Wireless defined by } \\
\text { software }\end{array}$ \\
\hline
\end{tabular}

\section{ARCHITECTURES}

\subsection{Network of Connected Objects through Services API}

With regard to the architecture of the IoT, since 2008 it has been possible to define possible structures of the same as that suggested by Grønbæk, which comprises a pair of logically distinct but closely coupled network domains, that is, the domains (scopes) of the backbone and network devices. Both environments can be directly serving Connected Objects (Grønbæk, $2008,4)$

An IoT architecture could consider that Connected Objects CO (consumer electronic devices) are linked directly to (ibid):

- The Internet backbone (at the network and IP layer), in which the IP network is located, Rendezvous Server RVS, Resolution Handler RH as extension of RVS, Object Naming Service ONS, integrated into an RVS as part of a Electronic Product Codes EPC Global Network and finally, Domain Name Server DNS. Likewise, they are in the IP network of the backbone hosting services, bootstrap, logging, rating and billing.

- Device networks: electronic devices connected to a LAN or wired internal network, which is linked to the Internet 
through a Gateway GW that has an Host Identity Tag HIT. This HIT Gateway is supported in the Host Identity Protocol HIP and allows global addressing of Connected Objects CO, while maintaining the use of IPv4 addresses.

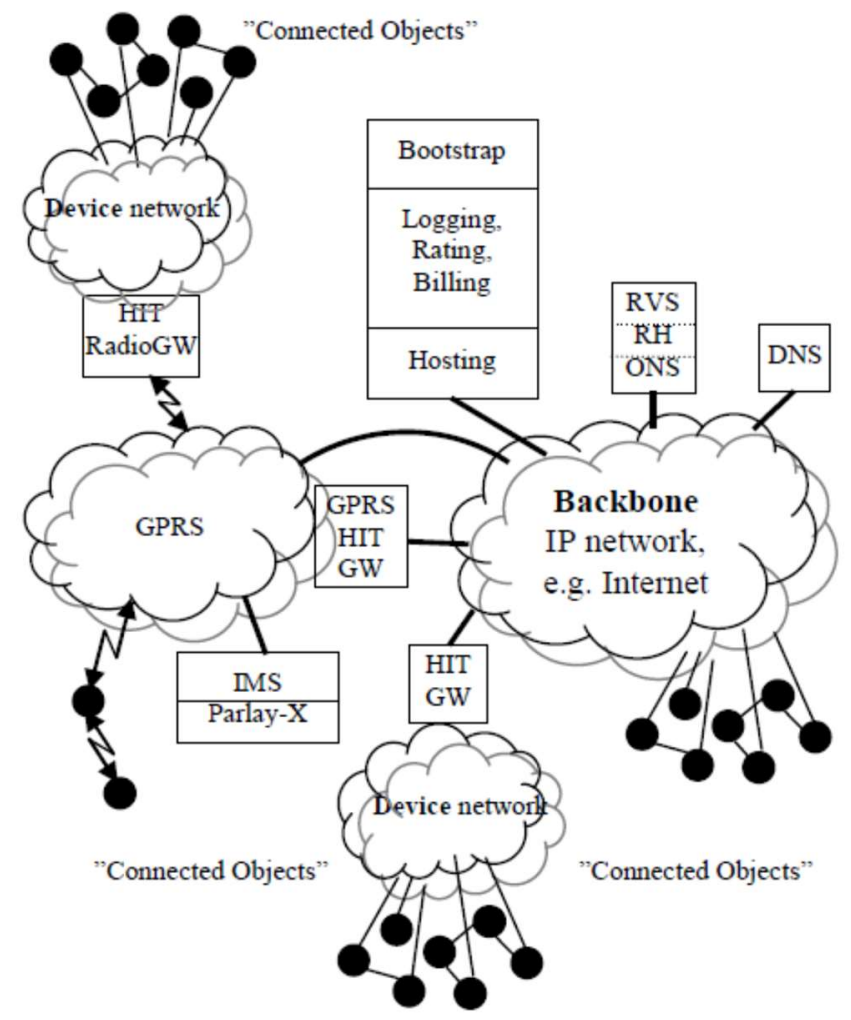

Figure 1: Related components in an IoT architecture (Grønbæk, 2008, 4)

When the network of devices has a wireless HIT GW (radio), use should be made of the General Packets Radio System GPRS to link to the Internet, which includes IP Multimedia Subsystem IMS services, Next Generation Networking NGN, APIs for telephone networks Parlay-X and finally, GPRS HIT GW servers (ibid.).

It is feasible that Wireless Connected Objects $\mathrm{CO}$ or belonging to the Global System for Mobile GSM communications, are not linked to an internal network and are directly linked to the GPRS service and through the latter, connect to the Internet backbone (ibid.).

\subsection{Stratified Network with Service Layer}

Duan, Chen and Xing propose a quality of service architecture based on the layered structure of the IoT. This architecture establishes a QoS agent in the lower layers that transmit the quality of service requirements, trying to guarantee the consistency, as well as efficiently use the existing QoS mechanisms in each layer $(2011,1)$. 


\begin{tabular}{|c|c|c|c|c|c|}
\hline $\begin{array}{c}\text { Intelligent } \\
\text { Transportation }\end{array}$ & $\begin{array}{l}\text { Intelligent } \\
\text { logistics }\end{array}$ & $\begin{array}{c}\text { Smart } \\
\text { City }\end{array}$ & $\begin{array}{c}\text { Precision } \\
\text { Agriculture }\end{array}$ & $\begin{array}{l}\text { Application } \\
\text { sub Layer }\end{array}$ & \multirow{2}{*}{$\begin{array}{c}\text { Application } \\
\text { and Service } \\
\text { Layer }\end{array}$} \\
\hline $\begin{array}{c}\text { Common } \\
\text { Middleware }\end{array}$ & $\begin{array}{c}\text { Data } \\
\text { Center }\end{array}$ & $\begin{array}{l}\text { Remote } \\
\text { Control }\end{array}$ & $\begin{array}{c}\text { Management } \\
\text { Service }\end{array}$ & $\begin{array}{c}\begin{array}{c}\text { Service su b } \\
\text { Layer }\end{array} \\
\end{array}$ & \\
\hline Intemet & Nireless netwo & & $\begin{array}{l}\text { Mobile } \\
\text { network }\end{array}$ & $\begin{array}{l}\text { Private } \\
\text { network }\end{array}$ & $\begin{array}{l}\text { Network } \\
\text { Layer }\end{array}$ \\
\hline WSN gateway & & Acc & cess Gateway & & \multirow{2}{*}{$\begin{array}{l}\text { Perception } \\
\text { Layer }\end{array}$} \\
\hline Sensor & RFIL & & arcode & er Device & \\
\hline
\end{tabular}

Figure 2: Architecture of the Internet of Things (Duan, et al., 2011, 1)

The layers of the previous figure are detailed below (ibid.):

- The perception layer corresponds to the connected objects CO (devices such as sensors, RFID, bar code readers, consumer electronics, etc.). These components are part of the physical layer of the OSI model.

- The network layer concerns the gateways of the Wireless Sensor Network WSN and access, as well as Internet IP addressing and local, mobile and WiFi networks, which is part of the link and network layer of the OSI model; i.e. of the backbone.

- The application and service layer consists of end-user software solutions with all the hosting, repository and intermediation services, which is equivalent to the transport, session, presentation and application layers of the OSI model.

- In this architecture, QoS service quality requirements have to do with three tasks: inquiry, control and monitoring. The respective examples are: the status of an item in intelligent logistics, remote control in intelligent traffic, record of environmental events. Likewise, a couple of QoS agents are implemented in the network and perception layers, which are regulated by a service quality installation manager (ibidem).

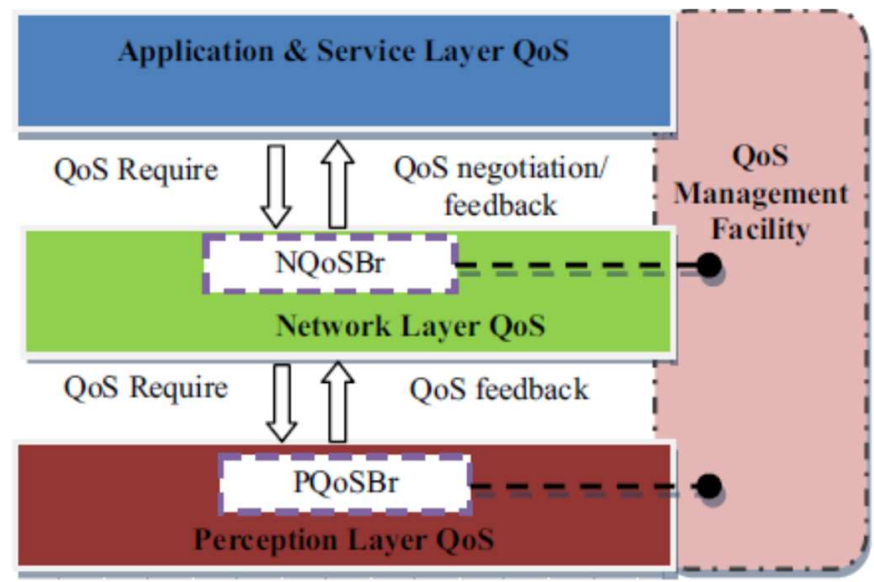

Figure 3: Quality of Services QoS in the architecture of the IoT (Duan, et al., 2011, 1)

\subsection{Networks Applied to Smart City}

Jin, Gubbi, Luo, and Palaniswami, have defined four different network architectures for the IoT, covering various smart city applications with their corresponding network requirements in terms of Quality of Service QoS which are visualized below. 
- Autonomous Network Architecture:

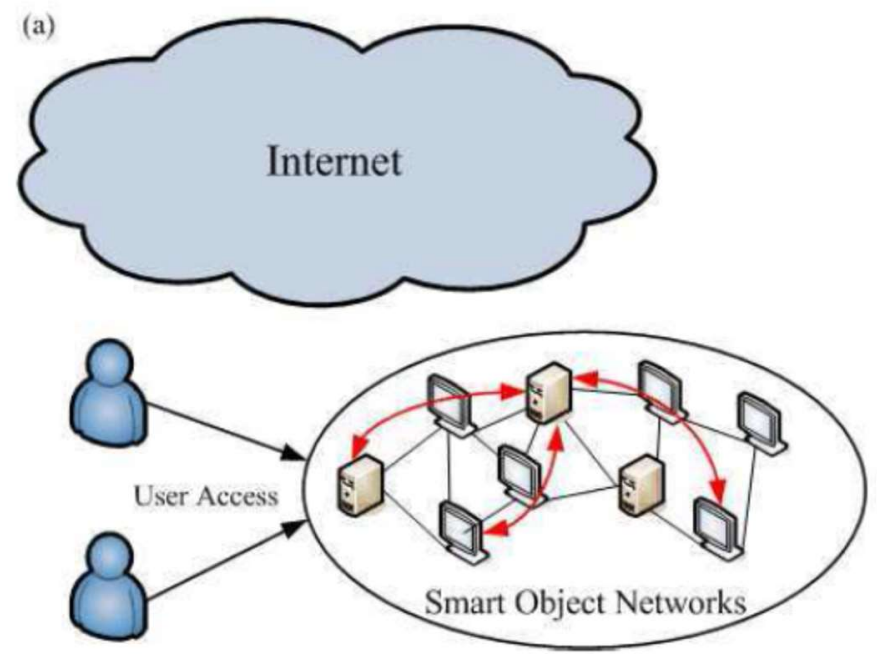

Figure 4: Autonomous Network Architecture (Jin, et al., 2012, 2)

- Ubiquitous Network Architecture:

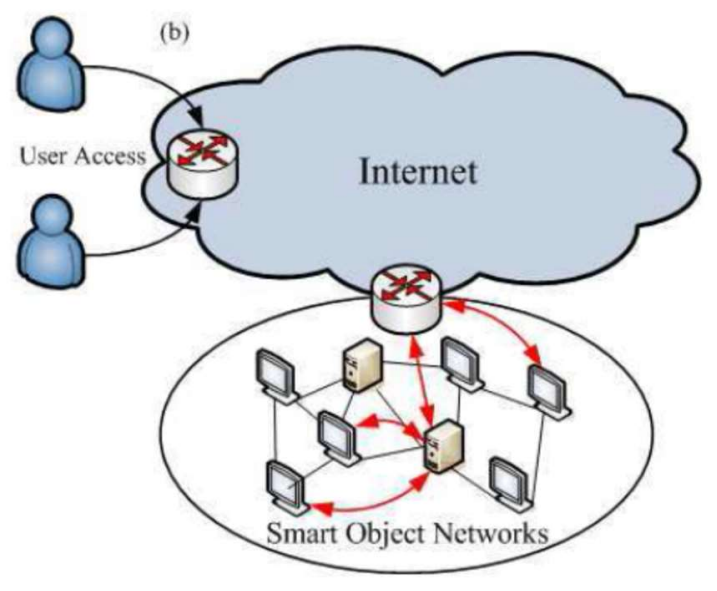

Figure 5: Ubiquitous Network Architecture (Jin, et al., 2012, 2)

- Network architecture with overlap application layer: 


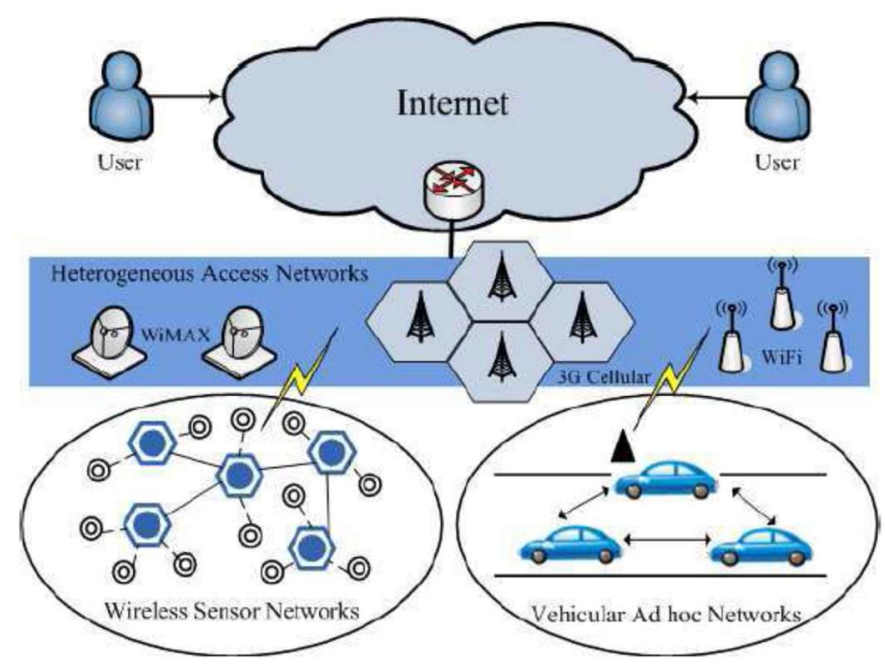

Figure 6: Network Architecture with overlap application layer (Jin, et al., 2012, 3)

- Service Oriented Network Architecture:

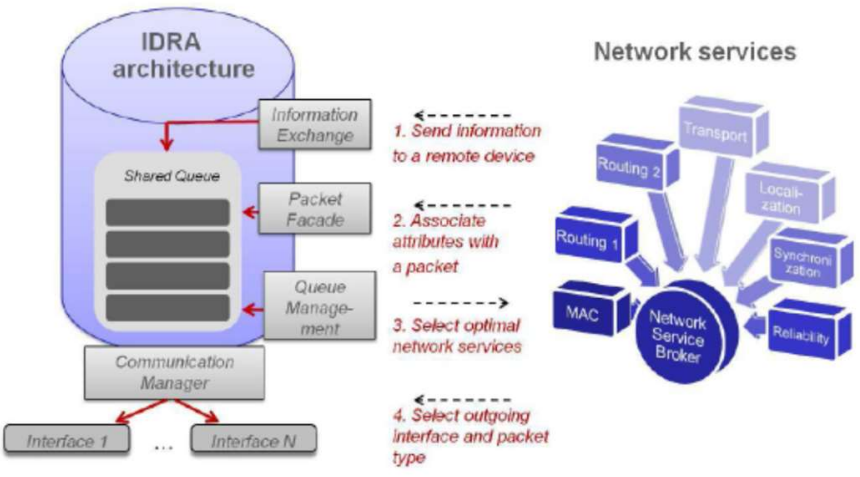

Figure 7: Architecture of Services-Oriented Network (Jin, et al., 2012, 4)

\subsection{Advanced long-term Evolution Network LTE-A}

Wali and Das formulated an architecture for the IoT supported in an Advanced Long Term Evolution Network LTE-A, by means of a programming algorithm that uses the heterogeneous network architecture (eNodeB macro and mini base stations) to reduce the collision rate and access delay caused by the density of IoT devices, by randomizing their access without affecting the Quality of Service QoS offered to mobile User Equipment UE, and that LTE-A is consolidating as a promising technology to serve the Internet of Things IoT, together with the needs of the UE, due to the high speed (rate) of data, low latency and priority services (Wali, 2014, 1). 


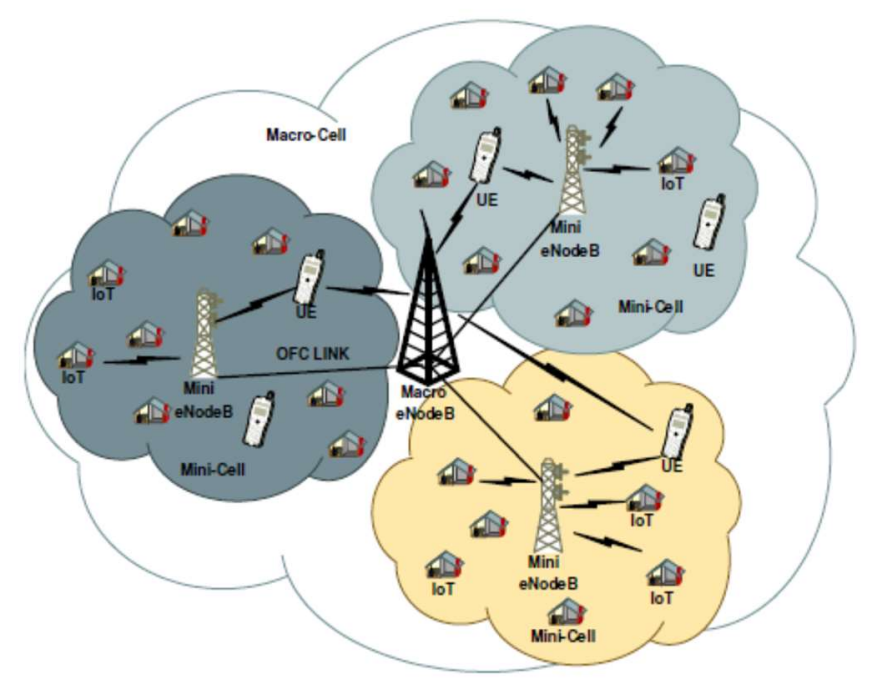

Figure 8: Framework of an LTE-A Network for access to the IoT (Wali, 2014, 3)

The authors identified the main challenges of incorporating IoT devices into the LTE-A. Such challenges are: the large number of IoT devices that try to access the network in a short time, the effect on communication existing mobile user equipment and finally, the need for additional bandwidth to accommodate said equipment (ibid.).

The results found by Wali and Das, in the simulation for a heterogeneous network within a single macro cell with 1 eNodeB macro and 4 mini base stations (mini cells) indicated that the proposed framework and programming reduced the collision rate for IoT devices by $80 \%$ and access delay by more than $50 \%$ during the LTE procedure to the Random Access Chanel RACH, as well as the improvement in Quality of Service QoS to User Equipment UE mobile phones, in comparison with the Access Barring AB scheme (ibidem).

\subsection{Service-Oriented Three-tier Network}

In the exposed architectures it has been observed that the Quality of the Service is a subject of great importance for the implementation of the same, given the great number of different devices and heterogeneous networks that make it difficult to satisfy the diverse QoS requirements. Li and Zhao corroborate this by proposing a three-tier planning QoS model of service-oriented IoT $(2014,1)$. 


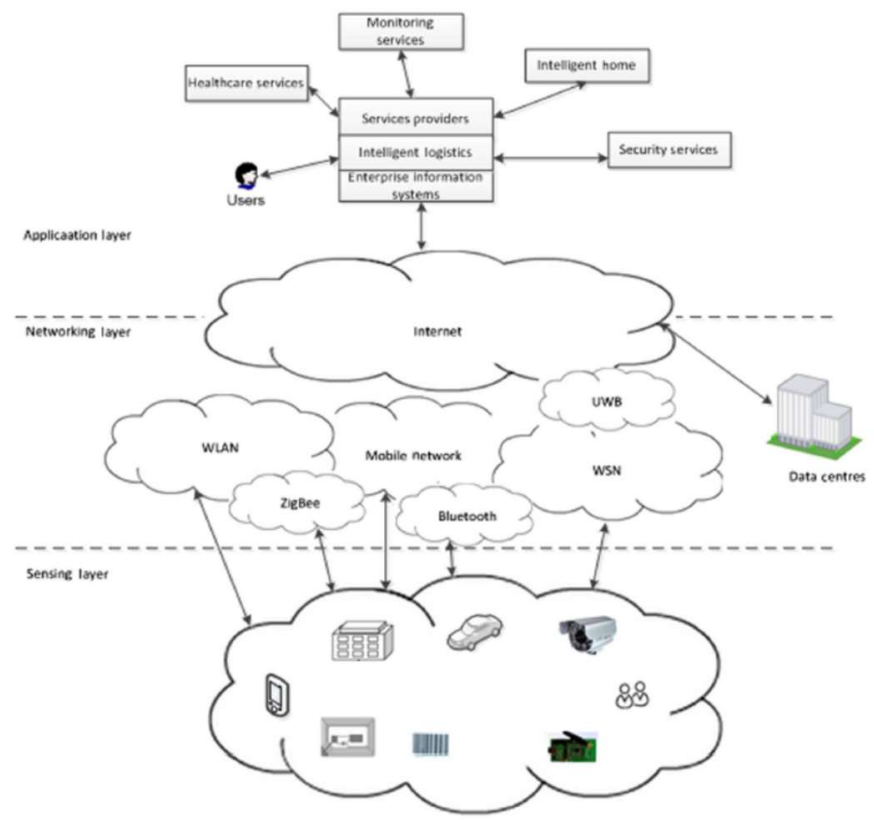

Figure 9: Basic architecture of the IoT ( $\mathrm{Li}$, et al., 2014, 3)

In the application layer, the quality of service programming scheme explores the optimal composition of the QoScompatible services using the knowledge of each of the service components. In the network layer, the model aims to deal with the programming of the environment of heterogeneous networks; in the detection layer (perception), it is the programming of information acquisition and the allocation of resources to different services ( $\mathrm{Li}$, et al., 2014, 1).

The quality of the service is optimized by establishing decision-making processes in both the network layer and the detection layer, as shown in the following figures:

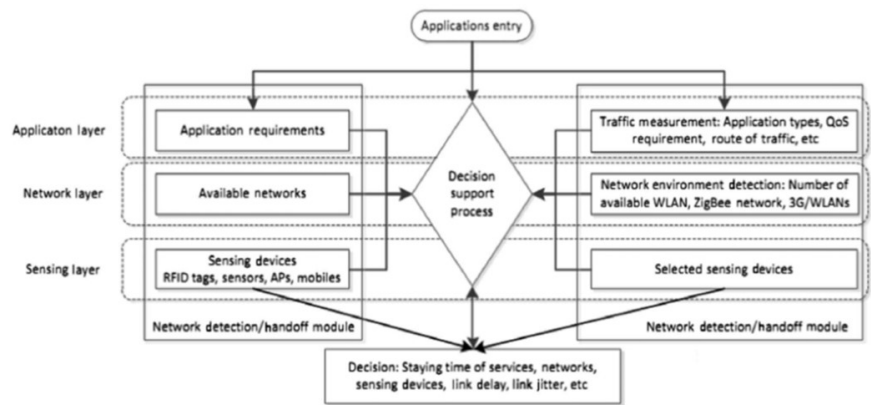

Figure 10: QoS decision in the IoT network layer (Li, et al., 2014, 4)

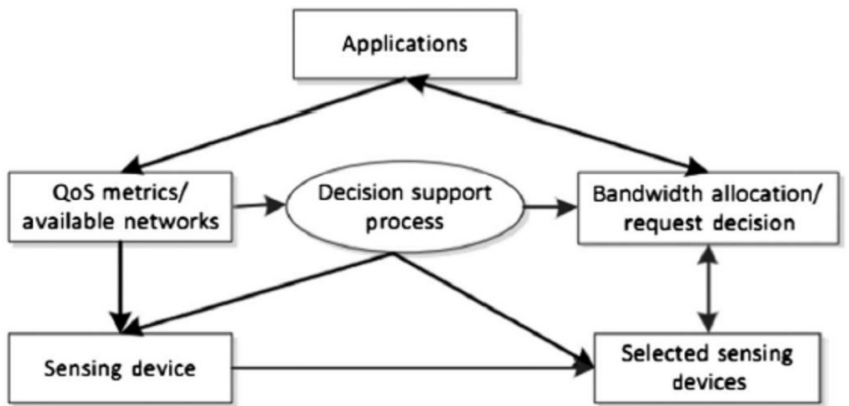

Figure 11: QoS decision in the IoT detection layer (ibid) 
Based on quality of service metrics defined in the IoT detection layer, such as the accuracy of the information, the accuracy of the detection, the energy consumption, the lifetime of the perception network and the cost, are establishes a monitoring module for decision making under a stochastic Markovian model, which optimizes the Quality of Service QoS in the service-oriented IoT. Under the same policy, metrics are defined for the application layer as service cost, performance time, service load and reliability. For the network layer following this policy, its metrics concern the allocation of bandwidth, the capacity of the network under restrictions, the rate of delay, performance and distortion and finally, energy efficiency (ibid, 8).

This allows the authors to conclude that the success rate in the composition of the service quality decreases linearly as the number of nodes in the IoT and the number of services increases. Likewise, the average rate of accuracy of information in the quality of service decreases linearly as the number of nodes in the IoT and the number of services increases (ibid.).

\subsection{Wireless Sensor Network WSN}

Given the great development that the Wireless Sensor Networks WSN have presented and the facility they offer to connect wireless sensors to the cloud through the Internet of Things IoT, it has led a group of researchers led by Syarifah Ezdiani in 2015 to Adapt the Quality of Service AQoS of the IoT through a system architecture of a testbed.

The test bench concept with AQoS for sensor networks in the cloud, provides a way for a flexible experimentation system that is able to react to dynamic changes in network conditions. By using network simulator tools to obtain performance information from the network based on historical data from a physical testbed, realistic prediction of network performance can be made, and physical network adjustment can be proposed (Ezdiani, 2015, 1). The following graph presents said testbed of AQoS.

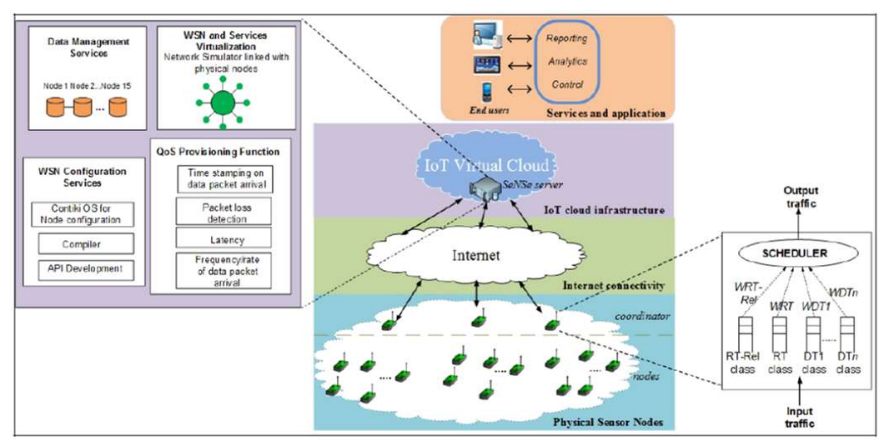

Figure 12: Architecture of the AQoS testbed (Ezdiani, et. Al., 2015, 3)

\subsection{Sensor Network with Message Queue Transport by Telemetry MQTT-SN}

The quality of service in IoT has another architectural approach developed by Govindan and Prakash (2015), consisting of a Network of Sensors with Message Queuing Telemetry Transport-Sensor Network MQTT-SN, which provides a efficient bandwidth for data transport under an unreliable wireless environment in terms of limited bandwidth.

Below are several MQTT-SN architectures for the devices to communicate with the server (PUBLISH): 


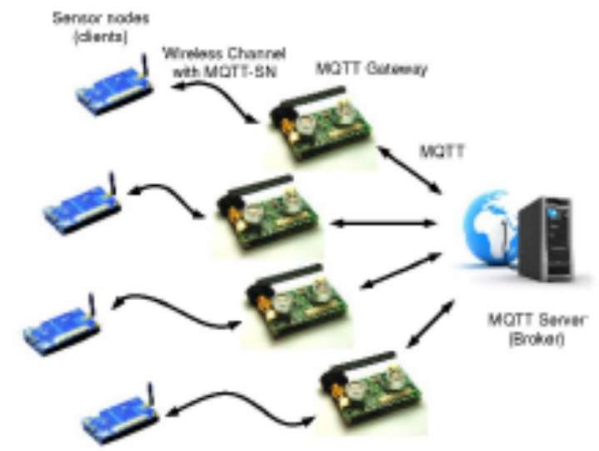

Figure 13: Transparent or simple gateway (Govindan, 2015, 2)

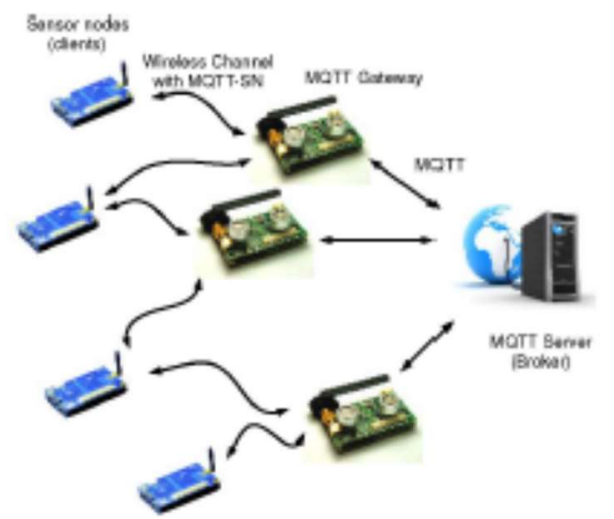

Figure 14: Hybrid or different gateway (ibid.)

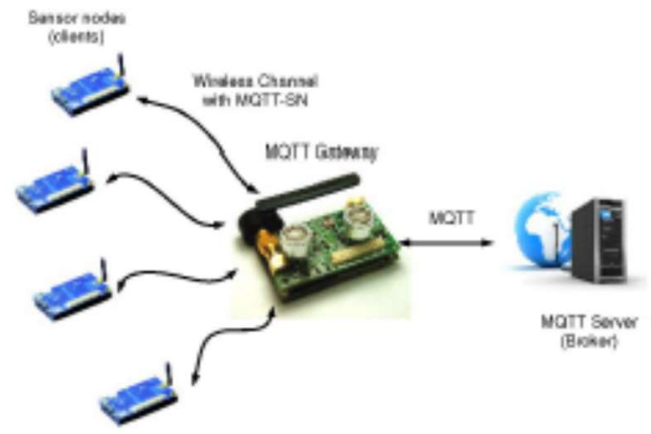

Figure 15: Aggregate or joined gateway (ibidem)

Now we can observe the Quality of Service model of level 1 (QoS-1 or at-least-once) for an end-to-end network system (ibid., 3): 


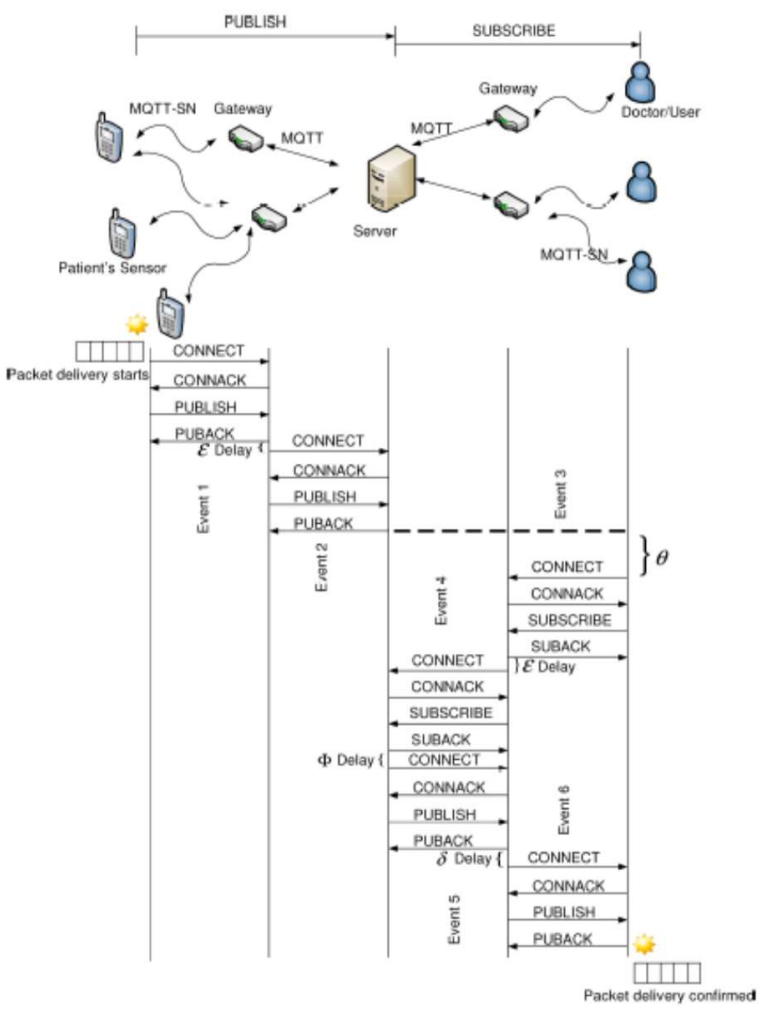

Figure 16: Quality of service model level 1 QoS-1 (Govindan, 2015, 3)

The level 0 Quality of Service model (QoS-0 or at-most-once) for an end-to-end network system is displayed below (ibidem):

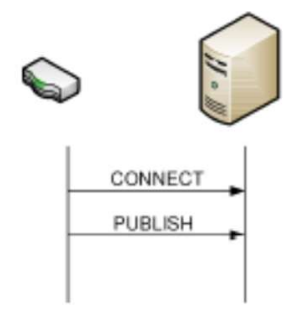

Figure 17: Quality of service model level 0 QoS-0 (ibid, 5)

Finally, the level 2 service quality model (QoS-2 or exactly-once) is observed for an end-to-end network system (ibid.):

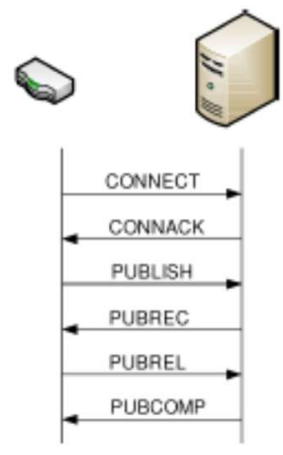

Figure 18: Quality of service model level 2 QoS-2 (ibid) 


\section{8. $\quad$ Fiber and Wireless Network FiWi}

Another aspect that has been studied within the quality of service in IoT is the implementation of Fiber and Wireless Networks FiWi, which as an integration of the fiber optic network and wireless access network, have attracted interest in intensive research and have enjoyed significant growth in their applications, in terms of network architecture, QoS provisioning, improved scalability, reliability and energy savings (Liu, et.al. , 2015, 1).

A couple of FiWi architectures for the IoT are shown below; one in the category of Radio on Fiber RoF and another type Radio and Fiber R\&F:

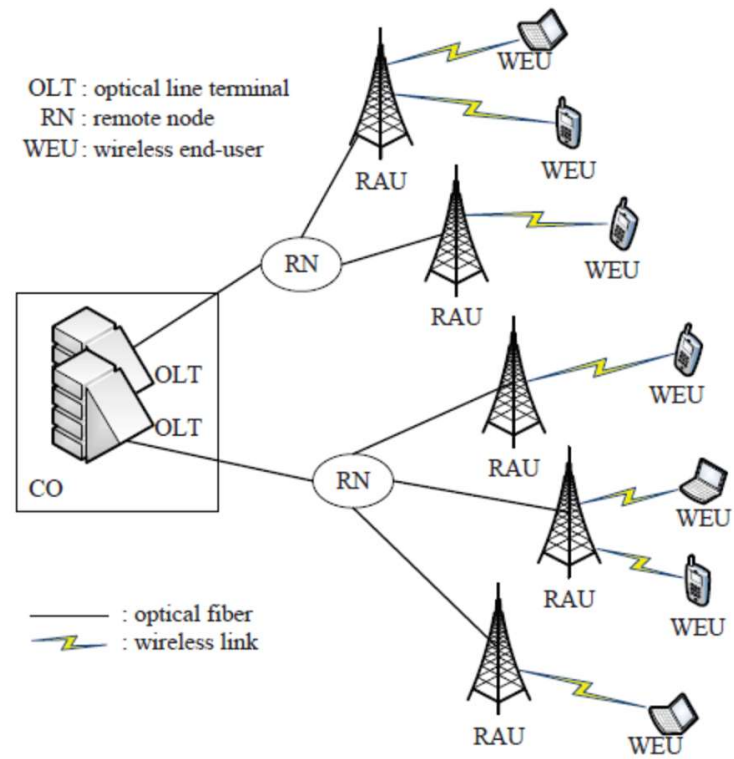

Figure 19: Integration of optical and wireless networks in the Radio on Fiber RoF category (Liu, et.al., 2015, 2)

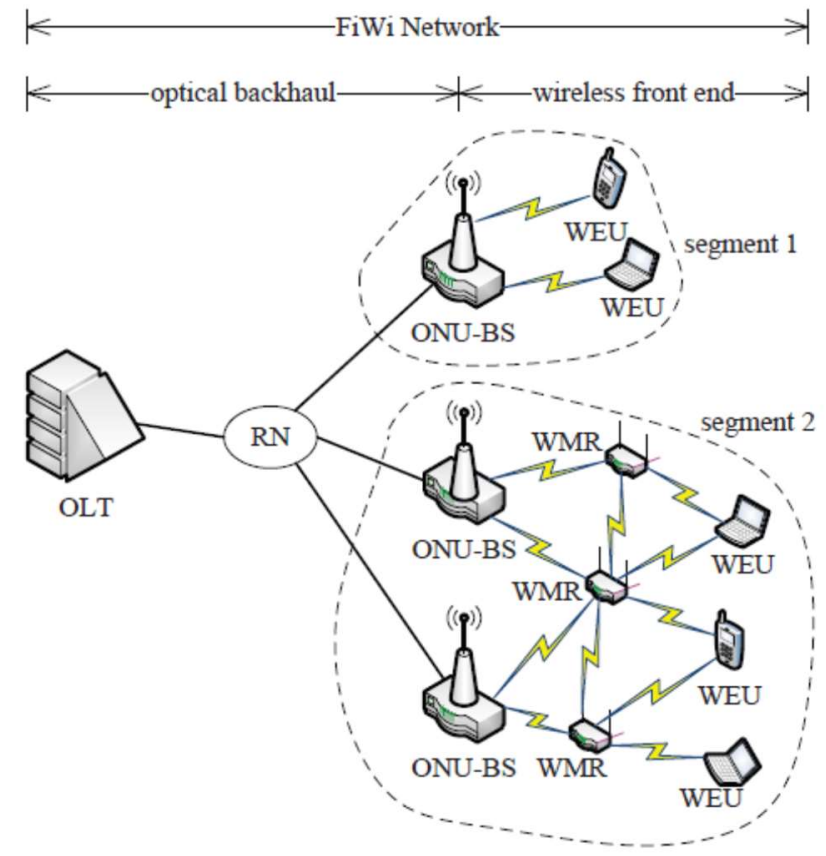

Figure 20: Integration of optical and wireless networks in the Radio and Fiber R\&F category (ibid, 4) 


\subsection{Software-defined Wireless Network}

To maximize the implementation of the Internet of Things IoT, a very detailed Quality of Service QoS support is required that satisfies: differentiated application needs, retrieval of context sensitive semantic information, and rapid deployment and easy resources, among many other objectives. These objectives can only be achieved if the IoT components can be managed end-to-end dynamically through: heterogeneous objects, transmission technologies and network architectures. According to El-Mougy, Software Defined Networking SDN is a new paradigm that provides powerful tools to address some of these challenges. Using a software-based control plane, SDNs introduce significant flexibility for resource management and adaptation of network functions. (El-Mougy, et.al., 2015, 1)

The components of the Internet of Things suggested by El-Mougy, et. al., with possible architectures of Networks Defined by Software SDN:

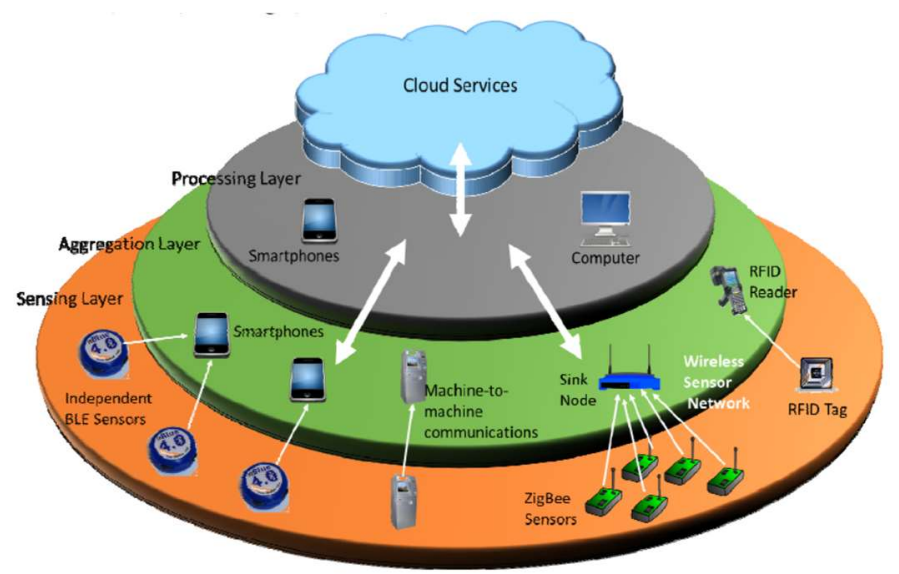

Figure 21: Components of the Internet of Things (El-Mougy, et.al., 2015, 21)

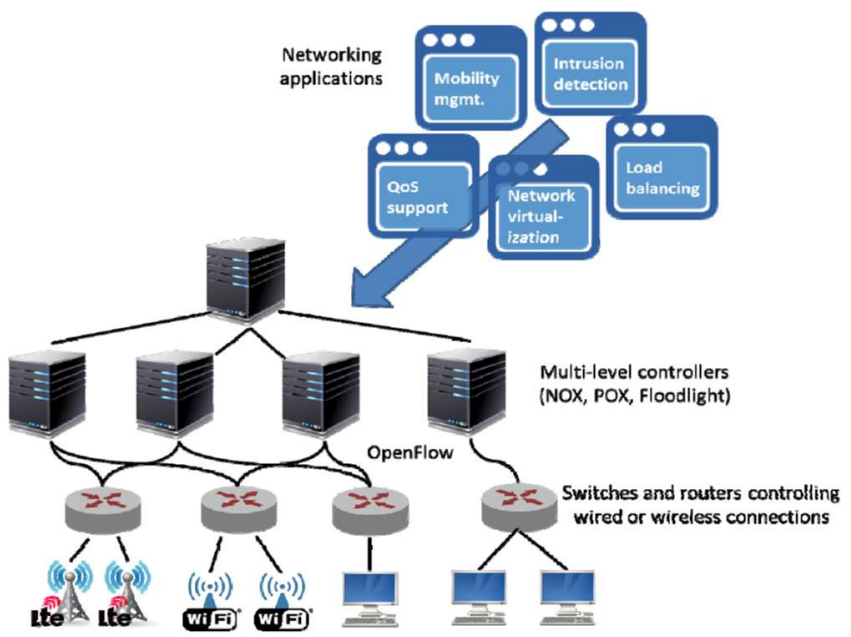

Figure 22: Components of Networks Defined by SDN Software (ibid, 3) 


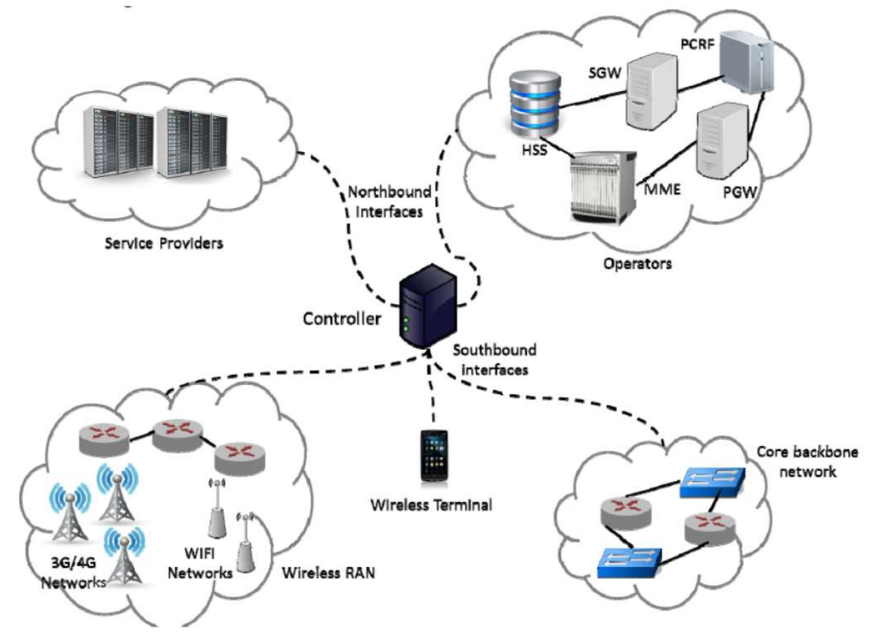

Figure 23: Architecture for a Software-Defined Wireless Network (WSDN) (ibid, 5)

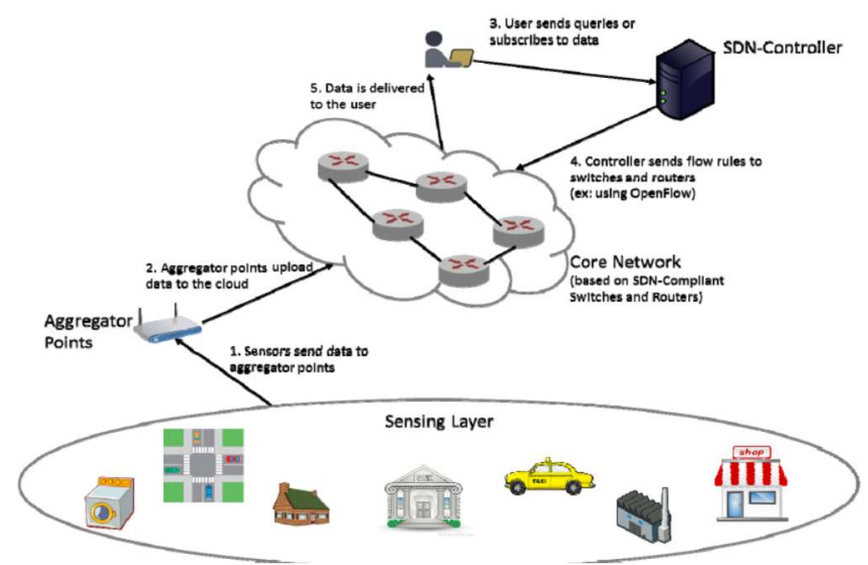

Figure 24: Architecture of an SDN based on ICN Information Centric Networks for the IoT (ibid, 6)

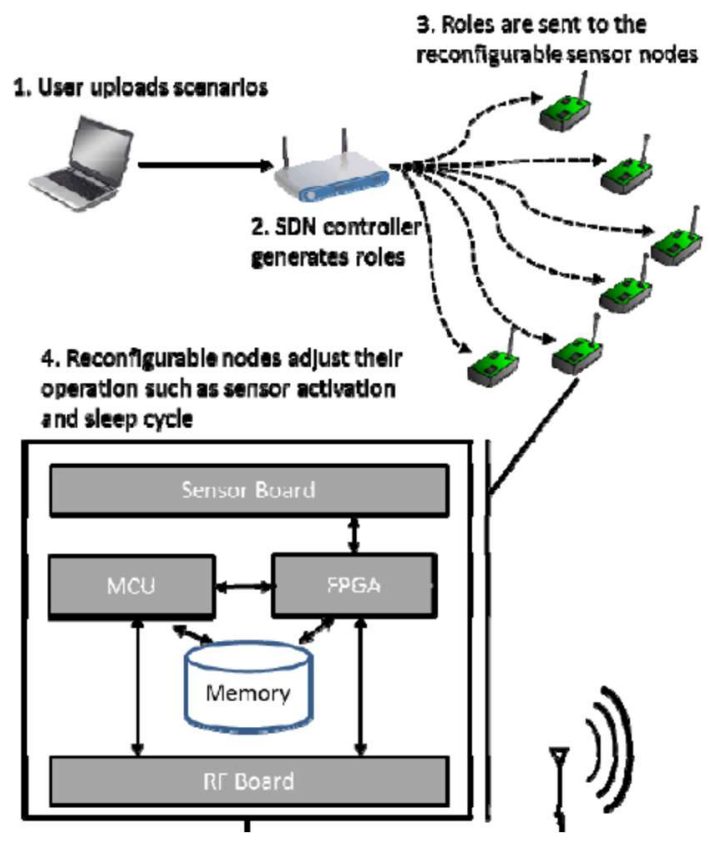

Figure 25: Reconfiguration of a sensor node to manage the detection layer in an SDN Network (ibid, 4) 


\section{DISCUSSION OF ARCHITECTURES}

From the description of the various functional architectures, the Quality of Service QoS is identified as a relevant characteristic, which acts as the metric that facilitates its estimation. Table 2 shows a balance of the same through the various characteristics of the aforementioned indicator such as the design approach, the connectivity model, the network hierarchy, the processing within the network, the complexity of the quality of service and the progress in defining the latter.

Table 2: Balance of the characteristics of functional architectures based on the QoS metric

\begin{tabular}{|c|c|c|c|c|c|c|c|c|}
\hline \multirow[b]{2}{*}{ No. } & \multirow[b]{2}{*}{ Author } & \multirow[b]{2}{*}{$\begin{array}{c}\text { Network } \\
\text { architecture }\end{array}$} & \multicolumn{6}{|c|}{ QoS Metric } \\
\hline & & & $\begin{array}{l}\text { Design } \\
\text { focus }\end{array}$ & $\begin{array}{c}\text { Connectivity } \\
\text { model }\end{array}$ & $\begin{array}{c}\text { Network } \\
\text { hierarchy }\end{array}$ & $\begin{array}{c}\text { Processing on } \\
\text { the network }\end{array}$ & $\begin{array}{c}\text { Complexity } \\
\text { QoS }\end{array}$ & $\begin{array}{c}\text { Progress in } \\
\text { the QoS } \\
\text { definition }\end{array}$ \\
\hline 1 & $\begin{array}{l}\text { Inge } \\
\text { Grønbæk }\end{array}$ & \begin{tabular}{|l|} 
Connection \\
through \\
services API \\
\end{tabular} & Evolutionary & IP & Yes & No & Low & Intermediate \\
\hline 2 & \begin{tabular}{|l|} 
Duan R., \\
Chen X., \\
Xing T. \\
\end{tabular} & \begin{tabular}{|l|} 
Stratified \\
with service \\
layer
\end{tabular} & Evolutionary & IP & Yes & Yes & High & Advanced \\
\hline 3 & $\begin{array}{|ll|}\text { Jin } & \text { J., } \\
\text { Gubbi } & \text { J., } \\
\text { et. al. } & \\
\end{array}$ & Autonomous & Evolutionary & $\begin{array}{l}\text { Compatible } \\
\text { with IP }\end{array}$ & Yes & No & Low & Intermediate \\
\hline 4 & $\begin{array}{|ll|}\text { Jin } & \text { J., } \\
\text { Gubbi } & \text { J., } \\
\text { et. al. } & \\
\end{array}$ & Ubiquitous & Evolutionary & IP & Yes & No & High & Intermediate \\
\hline 5 & $\begin{array}{|ll|}\text { Jin } & \text { J., } \\
\text { Gubbi } & \text { J., } \\
\text { et. al. } & \\
\end{array}$ & $\begin{array}{l}\text { Overlay } \\
\text { application } \\
\text { layer }\end{array}$ & Evolutionary & IP & Yes & Yes & Low & Advanced \\
\hline 6 & $\begin{array}{|ll|}\text { Jin } & \text { J., } \\
\text { Gubbi } & \text { J., } \\
\text { et. al. } & \\
\end{array}$ & $\begin{array}{l}\text { Service } \\
\text { oriented }\end{array}$ & $\begin{array}{l}\text { Clean } \\
\text { blackboard }\end{array}$ & $\begin{array}{l}\text { Compatible } \\
\text { with IP }\end{array}$ & Adaptable & Yes & High & Early stage \\
\hline 7 & $\begin{array}{l}\text { Wali P., } \\
\text { Das D. }\end{array}$ & \begin{tabular}{|l|} 
Long Term \\
Evolution \\
LTE \\
Advanced \\
\end{tabular} & Evolutionary & $\begin{array}{l}\text { Compatible } \\
\text { con IP }\end{array}$ & Yes & Yes & High & Advanced \\
\hline 8 & $\begin{array}{l}\text { Li L., Li } \\
\text { S., Zhao S. }\end{array}$ & \begin{tabular}{|l|} 
Service- \\
oriented \\
Three-layer \\
\end{tabular} & Evolutionary & IP & Adaptable & No & High & Intermediate \\
\hline 9 & \begin{tabular}{|l|} 
Ezdiani S., \\
Acharyya \\
I., \\
Sivakumar \\
S., Al- \\
Anbuky \\
A.
\end{tabular} & $\begin{array}{l}\text { WSN } \\
\text { wireless } \\
\text { sensors }\end{array}$ & Evolutionary & IP & Yes & No & High & Advanced \\
\hline 10 & $\begin{array}{l}\text { Govindan } \\
\text { K., } \\
\text { Prakash A. }\end{array}$ & $\begin{array}{l}\text { Sensors with } \\
\text { Message } \\
\text { Queue } \\
\text { Transport by } \\
\text { Telemetry } \\
\text { MQTT-SN } \\
\end{array}$ & Evolutionary & $\begin{array}{l}\text { Compatible } \\
\text { with IP }\end{array}$ & Yes & Yes & High & Intermediate \\
\hline 11 & \begin{tabular}{|l|} 
Liu J., \\
Guo H., et. \\
al.
\end{tabular} & \begin{tabular}{|l|} 
Fiber and \\
wireless \\
FiWi \\
\end{tabular} & $\begin{array}{l}\text { Clean } \\
\text { blackboard }\end{array}$ & $\begin{array}{l}\text { Compatible } \\
\text { with IP }\end{array}$ & Yes & No & High & Early stage \\
\hline 12 & $\begin{array}{l}\text { El-Mougy } \\
\text { A., et. al. }\end{array}$ & $\begin{array}{l}\text { Wireless } \\
\text { defined by }\end{array}$ & $\begin{array}{l}\text { Clean } \\
\text { blackboard }\end{array}$ & $\begin{array}{l}\text { Compatible } \\
\text { with IP }\end{array}$ & Adaptable & Yes & Half & Early stage \\
\hline
\end{tabular}




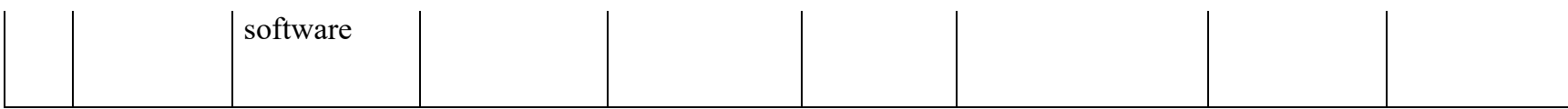

It can be seen in the table of models of functional architectures that the generality has an evolutionary design approach (75\%) with the exception of the service-oriented model, the FiWi fiber and software-defined model, whose perspective is clean slate (25\%) ). All the architectures have an IP connectivity model either total (50\%) or compatible (50\%), which is typical of the Internet. The network hierarchy is relevant in $75 \%$ of the architectures, except those oriented to mono and tri-layer services, as well as those defined by software $(25 \%)$.

The processing inside the network exists in $50 \%$ of the architectures, specifically in which software functionality is relevant, such as the layer models (50\%). Regarding the complexity of the quality of service, the results are heterogeneous for the different architectures, being high by $58 \%$, average by $17 \%$ and low by $25 \%$. Finally, progress in the definition of QoS is mixed, with $25 \%$ in the early stage, $42 \%$ in the intermediate stage and $33 \%$ in the advanced stage.

It is noteworthy that the wireless network architecture defined by software for the Internet of Things establishes a framework for the connectivity of devices, under a semantics that must be agreed between the various telecommunications organizations in the world, giving free rein to the massification of the services and functions provided by the various intelligent machines with their corresponding management, given the design characteristics of clean slate, IP compatible link, adaptable network hierarchy, moderately complex service quality and in an early stage, with processing in line in tasks of discovery, registration, monitoring and control of said electronic equipment.

\section{CONCLUSIONS}

The functional architectures of the Internet of Things reviewed present -in terms of their models- a support in both treatment and data transfer, being 33\% and 67\% respectively. Situation that leads to concentrate development efforts on the logical aspect of the IoT, given that it defines syntactic and semantic interoperability of the network for the connectivity of smart devices.

It is possible to carry out this by defining a conceptual framework that relates the various abstractions in a specific discourse universe -which is known as the ontology-, despite the various existing technologies in terms of treatment and transfer of information. data, which implies a revision about the different ontological models that concern the information sciences and communications as future work.

The functional architectures that most lend themselves to the task of defining a specific conceptual system are the software-defined wireless model and the service-oriented three-layer model, since they allow hosting in servers or gateways of the framework of the concepts or classes and their relationships, executing the aforementioned interoperability between the different machines.

\section{REFERENCES}

1. Grønbak, Inge. (2008). Architecture for the Internet of Things (IoT): API and interconnect. The Second International Conference on Sensor Technologies and Applications. Telenor R\&I.

2. Duan, Ren. Chen, Xiaojiang. Xing, Tianzhang. (2011). A QoS architecture for IoT. IEEE International Conferences on Internet of Things, and Cyber, Physical and Social Computing. DOI 10.1109/iThings/CPSCom.2011.125. 
3. Jin, Jiong. Gubbi, Jayavardhana. Luo, Tie. Palaniswami, Marimuthu. (2012). Network architecture and QoS issues in the Internet of Things for a smart city. International symposium on communications and information technologies ISCIT. Doi: 9781-4673-1157-1.

4. Wali, Prashant. Das, Debabrata. (2014). A Novel Access Scheme for IoT Communications in LTE-Advanced Network. IEEE ANTS 20141570023085.

5. Li, Ling. Li, Shancang. Zhao, Shanshan. (2014). QoS-Aware Scheduling of Services-Oriented Internet of Things. IEEE Transactions on Industrial Informatics, Vol. 10, No. 2, May 2014.

6. Ezdiani, Syarifah. Acharyya, Indrajit S. Sivakumar, Sivaramakrishnan. Al-Anbuky, Adnan. (2015). An IoT Environment for WSN Adaptive QoS. IEEE International Conference on Data Science and Data Intensive Systems. DOI: 10.1109/DSDIS.2015.28

7. Govindan, Kannan. Prakash A., Amad. (2015). End-to-end Service Assurance in loT MQTT-SN. 12th Annual IEEE Consumer Communications and Networking Conference (CCNC).

8. Liu, Jiajia. Guo, Hongzhi. Nishiyama, Hiroki. Ujikawa, Hirotaka. Suzuki, Kenichi. Kato, Nei. (2015). New Perspectives on Future Smart FiWi Networks: Scalability, Reliability and Energy Efficiency. IEEE Communications Surveys \& Tutorials. DOI: 10.1109/COMST.2015.2500960.

9. El-Mougy, Amr. Ibnkahla, Mohamed. Hegazy, Lobna. (2015). Software-Defined Wireless Network Architectures for the Internetof-Things. 40th Annual IEEE Conference on Local Computer Network. Florida, USA. DOI: 978-1-4673-6773-8.

10. Evans, Dave. (2011). Internet of Things. The next evolution of the Internet is changing everything. Technical report. Internet Business Solutions Group (IBSG) by CISCO.

11. Vermesan, Ovidio. Friess, Peter. (2013). Internet of Things: Converging Technologies for Smart Environments and Integrated Ecosystems. River Publishers. Denmark. URL: http://www.internet-of-thingsresearch.eu/pdf/Converging_Technologies_for_Smart_Environments_and_Integrated_Ecosystems_IERC_Book_Open_Access _2013.pdf

12. ETSI. (2013). ETSI TR 101584 V2.1.1 (2013-12). Technical Report. Machine to Machine Communications (M2M); Study on Semantic support for M2M Data. European Telecommunications Standards Institute. URL: https://www.etsi.org/deliver/etsi_tr/101500_101599/101584/02.01.01_60/tr_101584v020101p.pdf

13. ETSI. (2017). ETSI TS 103264 V2.1.1 (2017-03). Technical Specification. SmartM2M; Smart Appliances; Reference Ontology and oneM2M Mapping. European Telecommunications Standards Institute. URL: https://www.etsi.org/deliver/etsi_ts/103200_103299/103264/02.01.01_60/ts_103264v020101p.pdf 